\title{
Teaching technosphere safety and environmental culture at a technical university
}

\author{
$R$ Bazaliy $^{1, *}$ \\ ${ }^{1}$ Don State Technical University, Gagarin sq., 1, Rostov on Don, 344003, Russia
}

\begin{abstract}
The article discusses the psychological and pedagogical components of the environmental-cultural development of students of technical and humanitarian specialties, as well as cause-and-effect relationships of environmental problems of the largest industrial enterprises. The necessity of using control methods and modern technical means to ensure human security in the modern world is justified. The control effects on the elements of the technosphere space that support the biosphere and technosphere in a qualitative state are analyzed. The article reveals the prospects for common activities between the technical university and companies that are aimed at ensuring the necessary level of technosphere security.
\end{abstract}

\section{Introduction}

At the beginning of the 21 st century, the urgent need for the development of technosphere security has significantly increased, the protection of humans and the environment from the consequences of industrial activities is also very topical. The emerging threat of global climate warming, soil, air and water pollution, and the gradual depletion of natural resources require an expanded implementation of the environmental and environmental component in the education and upbringing of students of the Don State Technical University.

Taking into account the increased requirements for training bachelors of technical and humanitarian specialties in the conditions of traditional and distance learning, the research goal is relevant: the development of environmental culture and technosphere safety of students. To solve the psychological and pedagogical components of this problem, it is necessary to form environmental education and awareness of the cause-and-effect relationship of environmental problems to the successful professional activity of students, creating favorable conditions for the transformation of the biosphere and technosphere by man.

In the scientific discourse, the problems of environmental education and training, methodological aspects of environmental education are widely discussed, safe technological processes and production are investigated, and practical developments in the biosphere and technosphere transformed by man are summarized. S. Grumbach, O. Hamant put forward rules for solving global socio-ecological problems [1], A. Karabulut, E.

\footnotetext{
*Corresponding author: rv7bazalii@mail.ru
} 
Crenna, S. Sala evaluated the relationship between the ecosystem, water, food, land and energy [2], L. Buth, M. Juraschek, F. Cerdas, C. Herrmann noted the planning and design of production systems [3], C. Hsien, C. Foo, J. Low, and D. Tan improved the graphical algorithm for determining environmentally efficient ways to convert waste into resources [4], V. Moskvichev reviewed trends in the development of technical systems in terms of reliability, risk analysis, and safety [5], K. Volkart, C. Mutel, and E. Panos assessed the impact of global energy scenarios on the environment and health [6], D. Foo, R. Tan analyze methods for integrating processes to solve various problems related to emissions and the ecological footprint [7]. B. Rugani, D. Souza, and B. Weidema justified the integration of the cascade structure of ecosystem services into the causal methodology for life cycle assessment [8].

The problems of ecological culture, ecological education at different stages devoted to the work of many scientists. E. Asafova studied the effect of design and creative tasks to changing environmental culture of the students [9], E. Manolis, E. Manoli researched environmental projects, which influence on the cognitive and moral abilities of the students [10], J. Hickel considered the environmental efficiency of countries in human development [11], S. Otto, P. Pensini determined that environmental knowledge and connection with nature are linked together with environmental behavior [12], S. Otto, G. Evans, M. Moon, F. Kaiser noted the importance of developing environmental attitudes and behavior of children [13], E. Kallas, T. Solovjeva, L. Minakova justified the need for environmentally sound education in connection with global environmental problems [14], S. Findlow defends environmental concepts and social transformations as the basis of environmental sustainability [15], H. Hwang investigated the impact of the environmental context of teacher education [16], N. Ardoin, A. Bowers, and E. Gaillard investigated the contribution of environmental education to environmental conservation and quality [17].

\section{Materials and Methods}

During the research, the following methods were used: the study of scientific literature, analysis of psychological and pedagogical literature on the topics of environmental culture, environmental education and upbringing, and technosphere safety. Diagnostics of students in technical and humanitarian fields was carried out: the possibilities of environmental education for productive implementation, students interest in solving environmental problems, achieving cognitive and emotional results were studied. Surveys, testing, questionnaires, performing contextual tasks, studying the results of students practical activities, and comparing data on the research problem were conducted. The results of the study were obtained by a sample of 317 students of DSTU, of which 179 are trained in technical areas and 138 - in humanities.

\section{Results and discussion}

Bachelors of technical and humanitarian departments in the course of studying the discipline of a didactic purpose "Methodology of educational work" get acquainted with the concepts of environmental education, taking into account the changing needs of modern society. Studying the main problems of modern ecology, students of the Technical University various areas clearly present the living appearance of the biosphere and the cause-and-effect relationships of environmental problems that arose from the unfavorable interaction of the organism with the surrounding nature. Environmental knowledge obtained earlier by bachelors in the course of studying the discipline "Ecology" allows the staff of the department "Theory and methods of professional education" to expand the 
basics of rational use of nature, to form the ecological worldview of students and prepare them for the implementation of educational and professional activities.

System-active approach during the students' practical training at the largest industrial enterprises (LLC «Rostselmash» and JSC «Rostvertol») deepen a bachelor's understanding of nature management in people's practices, which is aimed at the safe use of modern technical means, as well as the rational use of natural resources, and the protection of the surrounding natural world. Students highly appreciated the dust-collecting filters installed at the Selmash plant, galvanic phosphating lines, modern treatment facilities that process concentrated solutions in storage tanks. The company uses modern technical means for the development of technosphere safety, improving the applicator-plant feeder, designed for the application of liquid mineral fertilizers. The company "Rostvertol" successfully implements activities related to environmental and technosphere safety. Significant financial investments were spent on corrosion protection and two anodic oxidation lines were launched to reduce the environmental hazard of production. The trainees noted the importance of creating new industrial landfills for recycling metal shavings, which will increase environmental safety.

After passing the bachelor's industrial practice at the enterprises of the southern region, we tested the trainees in order to identify what control effects on the elements of the technosphere space are able to maintain it in a high-quality state, which reduce the adverse impact on the environment, as well as what ways out of this situation they can offer, based on their ecological worldview. 84 students of technical and 62 - humanitarian directions of 3-4 courses noted the following (table.1), the data is given as a percentage.

Table 1. Control actions on elements of technosphere space.

\begin{tabular}{|c|c|c|c|}
\hline & & $\begin{array}{c}\text { technical } \\
\text { department }\end{array}$ & $\begin{array}{c}\text { humanitarian } \\
\text { department }\end{array}$ \\
\hline 1. & $\begin{array}{c}\text { It is correct to measure technological progress with the } \\
\text { endurance of the biosphere }\end{array}$ & 29 & 27 \\
\hline 2. & $\begin{array}{c}\text { To consider production activities, taking into account } \\
\text { the laws of nature }\end{array}$ & 31 & 29 \\
\hline 3. & $\begin{array}{c}\text { To know the constitutional basis of environmental } \\
\text { expertise }\end{array}$ & 21 & 23 \\
\hline 4. & $\begin{array}{c}\text { To take part in procedures of environmental impact } \\
\text { assessment for the nature }\end{array}$ & 19 & 21 \\
\hline
\end{tabular}

In our study, we used contextual tasks related to explaining the causes of man-made disasters at enterprises, the impact of external natural factors, low safety standards, and the irresponsibility of officials. Students noted the following measures to prevent man-made disasters: strict industrial discipline, assessment of production conditions in the event of an accident, trial evacuation of the population in an emergency. 95 bachelors of technical and 76 - Humanities majors of 1-2 courses analyzed the main negative factors of the biosphere and technosphere, answered the question: "What is the cause of problems of technosphere security?» as follows (tab.2), the data is given as a percentage. 
Table 2. The causes of the problems of technosphere safety.

\begin{tabular}{|l|l|c|c|}
\hline & & $\begin{array}{c}\text { technical } \\
\text { department }\end{array}$ & $\begin{array}{c}\text { humanitarian } \\
\text { department }\end{array}$ \\
\hline 1. & $\begin{array}{l}\text { Malfunction of equipment or improper handling of it by a } \\
\text { person }\end{array}$ & 26 & 29 \\
\hline 2. & Deterioration of material and natural resources & 28 & 25 \\
\hline 3. & $\begin{array}{l}\text { The unexpected appearance of a plentiful flow of energy, } \\
\text { the unwillingness of a person to this flow }\end{array}$ & 27 & 24 \\
\hline 4. & Human error and equipment failure & 19 & 22 \\
\hline
\end{tabular}

Respondents noted that if a person pollutes the environment and harms its ecological state, they should also restore the resources taken from nature i.e. clean the air, do not pollute the water, and control the chemical impact.

Interns of the DSTU together with their mentors, using modern methods, conducted environmental monitoring and assessment of the quality of the environment, independently investigated its individual characteristics, components of the natural environment used in human economic activity. Graduates' competent perception of phenomena related to industrial production and human activity in the natural environment allows them to successfully apply control methods for the environmental safety of production and become highly qualified professionals. Students of professional training noted their acquisition of practical skills necessary for the successful creation of favorable conditions for the individual and their transformation of the biosphere and technosphere.

Conducting a survey of interns in technical and humanitarian departments, we identified the positive aspects of long-term cooperation between the DSTU and industrial companies. Respondents noted the positive aspects of cooperation: representatives of companies select the right specialists and invest their knowledge and competencies in them from the first year of study, and students try to prove themselves in the workplace and successfully solve the issue of employment in the future. The management of large enterprises is interested in highly qualified specialists involved in the implementation of modern technologies, innovative design developments and technical re-equipment of factories.

An important component of the bachelor's environmental culture is a responsible attitude to the environment. Modern society needs young specialists who possess moral attitudes in behavior and attitude to the surrounding natural world, synergistic and activitybased approaches to environmental education. The value orientations of young people, their worldview positions, and assessments of the state of environmental safety of production will largely determine the ways of developing a stable state of society in the future. In the course of a survey of 179 students of technical and 138 - humanitarian areas of DSTU, we identified what they see as the need and meaning of developing environmental culture and technosphere safety of students (table.4). Data is given as a percentage.

Table 3. The meaning of development of ecological culture and technosphere safety of students.

\begin{tabular}{|c|l|c|c|}
\hline & \multicolumn{1}{|c|}{$\begin{array}{c}\text { technical } \\
\text { department }\end{array}$} & $\begin{array}{c}\text { humanitarian } \\
\text { department }\end{array}$ \\
\hline 1. & $\begin{array}{l}\text { Human awareness of the interdependence and interrelation } \\
\text { of people and nature }\end{array}$ & 17 & 19 \\
\hline 2. & $\begin{array}{l}\text { Correct assessment of the current state of environmental } \\
\text { problems }\end{array}$ & 32 & 28 \\
\hline 3. & $\begin{array}{l}\text { Identification of the causes of dangerous man-made } \\
\text { accidents }\end{array}$ & 27 & 19 \\
\hline 4. & $\begin{array}{l}\text { Striving to have a positive impact on qualitative changes in } \\
\text { the biosphere and technosphere }\end{array}$ & 24 \\
\hline
\end{tabular}


In our study, the content of environmental culture of students identified activity, creative, value and cognitive elements.

The activity element of environmental culture reflects the skills and abilities, ways to implement practice-oriented types of environmental activities. It is aimed at modeling safe technological processes and production, at mastering practical skills for the preservation of people's health, using control and forecasting methods, and modern technical means.

The creative element requires mastering environmental skills, skills at the creative and research level, showing readiness to explore dangerous technological processes and production, finding solutions to man-made problems, and rational use of natural resources.

The value element is aimed at positive introduction to environmental values, development of motivation and personal experience of emotional and value attitude to the surrounding nature. The educational process has developed a system of practical exercises, contextual tasks that increase motivational, emotional, and value relationships. Students of technical and humanitarian specialties during their studies form their own evaluative attitude to the world around them and practical environmental activities. Bachelors participate in various environmental activities aimed at developing and ensuring the necessary level of technosphere safety. students embody the principles and rules of careful attitude of society to the world around them.

The cognitive element reflects the complex of environmental knowledge obtained, which is the main element of the environmental consciousness of bachelors. Environmental knowledge contributes to the formation of an image of the surrounding natural world in the minds of students and justifies purposeful practice-oriented activities. In the ecological culture of students, the most common concepts, ideas, environmental laws of environmental conservation, life facts and observations, ideas about the connection of the natural world.

Today, relevant topics are related to the development of the student's personality, his practical activities and interaction with natural nature, with ways of designing, mastering technologies and techniques for preventing technosphere risks, eliminating the consequences of industrial enterprises ' production activities, and emergency situations. In practical environmental activities, students of the technical University form a system of environmental values, master cognitive information of environmental orientation, guided by their own motives and values, create an individual program of creative research activities.

Environmental education of bachelors is based on the perspective environmental interests of students, forms of independent creative activity, individual environmental knowledge, which are an important part of the adult life of the younger generation. Students ' environmentally practice-oriented activities model processes and technologies that reduce the impact of agricultural processes and industrial technologies on the natural world around them. Educational environmental activities of bachelors form the experience of acquiring research information, students analyze the cause-and-effect relationships of environmental problems, identify objects of nature that require its support in a qualitative state. Students ' environmental activities during their internship at the largest enterprises of the southern region are aimed at gaining experience in value-motivational orientations and evaluativevolitional judgments, decision-making and behavior, and discussing the consequences of man-made accidents.

By accumulating experience in the emotional sphere through contact with natural nature, students of technical and humanitarian fields form an ecological attitude. The creative and research part of the environmental culture of bachelors develops their ability to independently assess the risk and danger, the desire to normalize the anthropogenic impact and the creative transformation of the biosphere and technosphere by man. Search and environmental activities provide for active independence of students, joint discovery of environmental knowledge and ways of action that preserve human health in the modern world. Performing various types of practice-oriented environmental activities forms 
students ' ways of professional activity, applying the knowledge gained in solving educational and creative tasks, and contextual tasks. Students ' value and environmental activities contribute to the acquisition of experience in value judgments and value orientations. Students critically assess the state of the natural world, discuss the consequences of human economic activity. Identification with natural objects, making forecasts, designing technologies to prevent man-made risks contributes to creating a sensual image of the natural world, a sense of unity and harmony of the surrounding nature and man, mastering practical and environmental skills, forming ecological and cultural needs and interests, and acquiring environmental experience through creative and environmental reinterpretation.

\section{Conclusion}

The introduction of the disciplines "Ecology" and " Methodology of educational work" in the curriculum for students of technical and humanitarian departments helps to carry out research confirming the regularities of the influence of industrial centers on the living systems of the planet. To feel the need for harmonious co-development of humanity and the surrounding nature and to participate actively in the development of the biosphere and technosphere are the tasks of common events by public figures of the DSTU and the largest companies in the southern region. The state is interested in developing the environmental professionalism of graduates of the DSTU, in their ability to make constructive, rational and technological decisions taking into account the environmental safety of production, the preservation of natural and resource potentials of the country.

Increasing the level of environmental culture required in the professional activities of students of technical and humanitarian departments helps to solve economic problems and apply environmental restrictions, taking into account the objective need for the survival of mankind and the preservation of the technosphere security of the planet.

\section{References}

1. S. Grumbach, O. Hamant, Anthropocene 30, 100245 (2020)

2. A.A. Karabulut, E. Crenna, S. Sala, Journal of Cleaner Production 172, 3874e38893875 (2018)

3. L. Büth, M. Juraschek, F. Cerdas, C. Herrmann, Procedia CIRP 90, 256-261 (2020)

4. C. Hsien, C.K. Foo, J.S.C. Low, D.Z.L. Tan, Procedia CIRP 90, 115-120 (2020)

5. V.V. Moskvichev, Procedia Structural Integrity 13, 2114-2119 (2018)

6. K. Volkart, C.L. Mutel, E. Panos, Sustainable Productionand Consumption 16, 121133 (2018)

7. D.C.Y. Foo, R.R. Tan, Process Safety and Environmental Protection 103, 291-307 (2016)

8. B. Rugani, D.M. Souza, B. Weidema, Science of the Total Environment 690, 12841298 (2019)

9. E.V. Asafova, Procedia - Social and Behavioral Sciences 191, 2329 - 2333 (2015)

10. E.N. Manolis, E.N. Manoli, Journal of Cleaner Production 279, 123614 (2021)

11. J. Hickel, Ecological Economics 167, 106331 (2020)

12. S. Otto, P.M. Pensini, Global Environmental Change 47, 88-94 (2017) 
13. S. Otto, G.W. Evans, M.J. Moon, F. Kaiser, Global Environmental Change 58, 101947 (2019)

14. E.V. Kallas, T.P. Solovjeva, L.Y. Minakova, Procedia - Social and Behavioral Sciences 200, $453-459$ (2015)

15. S. Findlow, Ecological Economics 157, 373-381 (2019)

16. H. Hwang, Teaching and Teacher Education 43, 1-14 (2014)

17. N.M. Ardoin, A.W. Bowers, E. Gaillard, Biological Conservation 241, 108224 (2020) 